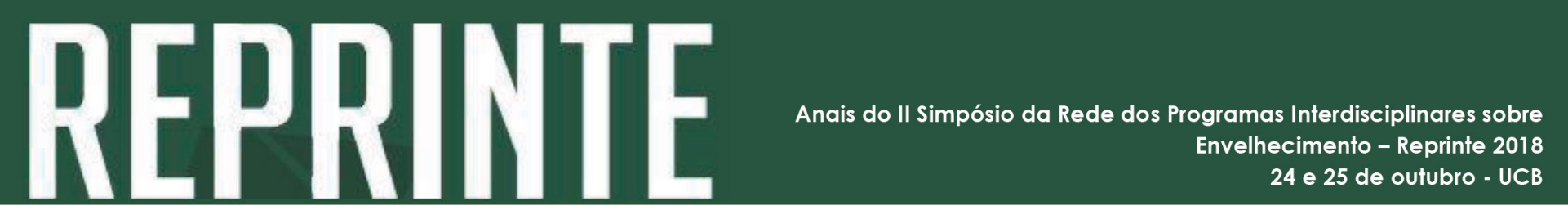

http://dx.doi.org/10.5335/rbceh.v16i1.9911

\title{
18) Guia de Agulhas para Transdutores Lineares e Convexos para Punção da Tireoide Guiada por Ecografia: "Ecothyrohealth"
}

\author{
Fernanda Silveira Tavares ${ }^{1}$, Fernando José Silva de Araújo'; \\ Gustavo de Azevedo Carvalho ${ }^{2}$, Karla Helena Coelho Vilaça e Silva²
}

\section{Resumo}

Introdução: Nódulos tireoidianos são muito prevalentes, sobretudo quando se empregam métodos sensíveis de imagem1. Atualmente o método de escolha para fazer a distinção entre benignidade e malignidade, considerado como padrão-ouro, é a punção aspirativa com agulha fina guiada por ecografia2. Neste, ecografia e coleta de material são feitos concomitantes. Quando se comparam grupos etários diferentes nas mãos de um mesmo examinador, observa-se que os extremos de idade são menos colaborativos 3 quer por questões fisiológicas, quer por comorbidades presentes, justificando assim um quantitativo maior de resultados insatisfatórios ou inconclusivos4. Considerando que os idosos são o grupo onde a prevalência de nódulos da tireoide é maior, faz-se justificável a necessidade de métodos alternativos de diagnóstico ou, ainda, melhora do procedimento convencional, objetivando melhor acurácia, conforto e menos ansiedade ao paciente acometido e seus familiares5,6. Esse projeto propõe o uso de um dispositivo acoplado ao transdutor da ecografia permitindo que, ao ser detectado o nódulo, o examinador acione um gatilho que possa coletar a amostra citológica, proporcionando maior comodidade e aumentando a precisão do procedimento. Materiais e métodos: O presente projeto far-se-á em duas etapas. Primeiro, para desenvolvimento do dispositivo, empresas especializadas serão consultadas para verificação de interesse, disponibilidade, custo e especificações gerais, incluindo criação de logo e patente. O nome sugerido será "Ecothyrohealth. Orçamento: O dispositivo em questão deverá ser orçado pelo desenvolvedor e irá depender de algumas variáveis sendo que o custo dependerá, principalmente, do material escolhido para confecção do mesmo. Resultados esperados: Considerando o impacto negativo das citologias tireoidianas com resultados insatisfatórios seja por necessidade de refazer o procedimento, seja por ansiedade gerada mediante dúvida de diagnóstico, um dispositivo seguro que aumente a acurácia das punções será de grande valia na prática clínica diária, especialmente na abordagem dos idosos, onde a dificuldade técnica para a coleta de material é maior.

Palavras-chave: ecografia da tireoide, punção, nódulo tireoide em idosos, citologia insatisfatória.

1 Doutoranda no Programa de Pós-Graduação em Gerontologia da Universidade Católica de Brasília e professora no curso de Medicina. Endereço para correspondência: QS 07 Lote 01 - EPCT - 71966-700 - Águas Claras - Taguatinga - DF. Emails (na ordem em que aparecem): fernanda.endocrino@gmail.com; fernandosjsaraujo@gmail.com.

2 Professores do Programa de Pós-Graduação em Gerontologia da Universidade Católica de Brasília. Emails (na ordem em que aparecem): carvalhobsb@hotmail.com; 


\section{Introdução}

Nódulos tireoidianos são muito prevalentes, sobretudo quando se empregam métodos sensíveis de imagem (ROSÁRIO et al, 2013). Atualmente o método de escolha para fazer a distinção entre benignidade e malignidade, considerado como padrão-ouro, é a punção aspirativa com agulha fina guiada por ecografia (GUTH et, 2009). Neste, ecografia e coleta de material são feitos concomitantes. Quando se comparam grupos etários diferentes nas mãos de um mesmo examinador, observa-se que os extremos de idade são menos colaborativos (MANDEL, 2004) quer por questões fisiológicas, quer por comorbidades presentes, justificando assim um quantitativo maior de resultados insatisfatórios ou inconclusivos (MORENO at al, 1996). Considerando que os idosos são o grupo onde a prevalência de nódulos da tireoide é maior, faz-se justificável a necessidade de métodos alternativos de diagnóstico ou, ainda, melhora do procedimento convencional, objetivando melhor acurácia, conforto e menos ansiedade ao paciente acometido e seus familiares (CRUZ et al. 2015; HAUGEN et al, 2016). Esse projeto propõe o uso de um dispositivo acoplado ao transdutor da ecografia permitindo que, ao ser detectado o nódulo, o examinador acione um gatilho que possa coletar a amostra citológica, proporcionando maior comodidade e aumentando a precisão do procedimento.

\section{Materiais e métodos}

O presente projeto far-se-á em duas etapas. Primeiro, para desenvolvimento do dispositivo, empresas especializadas serão consultadas para verificação de interesse, disponibilidade, custo e especificações gerais, incluindo criação de logo e patente. O nome sugerido será " $E c o-$ thyrohealth.

\section{Orçamento}

O dispositivo em questão deverá ser orçado pelo desenvolvedor e irá depender de algumas variáveis sendo que o custo dependerá, principalmente, do material escolhido para confecção do mesmo.

\section{Resultados esperados}

Considerando o impacto negativo das citologias tireoidianas com resultados insatisfatórios seja por necessidade de refazer o procedimento, seja por ansiedade gerada mediante dúvida de diagnóstico, um dispositivo seguro que aumente a acurácia das punções será de grande valia na prática clínica diária, especialmente na abordagem dos idosos, onde a dificuldade técnica para a coleta de material é maior. 


\section{Needle Guide for Linear and Convex Transducers for Ultrasound Guided Thyroid Puncture: "Ecothyrohealth"}

Keywords: thyroid ultrasound, puncture, thyroid nodule in the elderly, unsatisfactory cytology.

\section{Referências}

CRUZ F. J. et al. Perfil dos pacientes com nódulos tireoidianos submetidos à punção aspirativa por agulha fina. Interfaces Científicas - Saúde e Ambiente; 3: 47-56, fev.2015.

GUTH S., THEME U., ABERLE J. Very high prevalence of thyroid nodules detected by high frequency (13 MHz) ultrasound examination. Eur J Clin Invest.;39:699-706, 2009.

HAUGEN BR et al. 2015 American Thyroid Associatin Management Guidelines for Adult Patients with Thyroid Nodules and Differentiated Thyoid Cancer. Thyroid, 1, 2016.

MANDEL S.J. A 64-year-old woman with a thyroid nodule. JAMA 292:2632-2642, 2004.

MORENO L. at al. Rendiemiento comparative entre biopsia y citologia obtenidas por aspiración con aguja fina en nódulos sólidos del tiroides. Rev. Méd. Chile; 124 (11):1315-9, nov.1996.

ROSÁRIO P.R. et al. Nódulo tireoidiano e câncer diferenciado de tireoide: atualização do consenso brasileiro. Arq. Bras. Endocrinol. Metab. vol. 57, no. 4, São Paulo, June 2013. http://dx.doi.org/10.1590/S000427302013000400002 . 